\title{
Policy Making Challenges in the scope of Oral Health in Developing Countries A Qualitative Study of the Islamic Republic of Iran
}

Mohammad Mohammadpour

Shiraz University of Medical Sciences

Peivand Bastani ( $\square$ bastanip@sums.ac.ir)

Shiraz University of Medical Sciences https://orcid.org/0000-0002-0412-0267

Arash Ghanbarzadegan

The University of Adelaide

Jamshid Bahmai

Shiraz University of Medical Sciences

Research article

Keywords: oral health, developing country, policy making, strategy

Posted Date: November 5th, 2019

DOI: https://doi.org/10.21203/rs.2.16823/v1

License: (c) (i) This work is licensed under a Creative Commons Attribution 4.0 International License.

Read Full License 


\section{Abstract}

Background As the strategies proposed for oral health improvement in developed countries do not adapt for the setting of the developing ones, this study is to identify the challenges of oral health policy making in developing countries.

Methods It was a qualitative study conducted in 2019 in Iran as a middle-eastern developing country. The study population included all the experts who have enough experience in the scope and have the eagerness to participate. Snowball sampling was used to include the participants and after 12 semistructured interviews saturation was achieved. Guba and Lincoln criteria containing acceptability, validity, reliability, and transferability were used to assure the study reliability and finally five-stage framework analysis method was used to analyze the data.

Results The analysis of the results of the interviews resulted in the identification of 7 main themes and 20 sub-themes as the main challenges of achieving oral health in a developing country. The main themes identified were: policy making, implementing, educational, stewardship, prevention, insurance, and resource allocating.

Conclusion: According to the present results, it seems that national coverage of oral health and the integration of these services in prevention ones and serious attention to the private sector can be considered as the most important strategies for achieving improved oral health.

\section{Introduction}

In spite of the announcement of World Health Organization, for everyone health by 2000 , as well as significant progress in many fields of public health, there has been little progress in the prevention and improvement of oral health and the burden of diseases is increasingwhich is referred to as the silent epidemic [1]. A study on the burden of diseases in 2017 shows that oral diseases affect more than half of the world's population [2] and untreated caries in children is estimated at 560 million cases worldwide [2]. In Iran, according to the latest National Oral Health Survey on oral health in 2012, the number of Decayed, Missed and Filled Teeth (DMFT) in primary age groups of children aged 5-6 was 5.16 in the whole country. This index has been reported in urban and rural areas 4.94 and 5.78, respectively [2].

On the other hand, other evidence shows that achieving oral health in different communities poses a great economic burden, for example, a national survey of household expenditure surveys in Iran showed that $15.5 \%$ of total household health expenditure has been related to oral health expenditure [3]. These statistics are more important regarding the lack of basic benefit packages and insurance coverage to pay the costs of oral diseases in Iran [4].

In addition to the above, other evidence suggests that poor oral health may lead to inevitable consequences, including difficulties in swallowing, sleeping, socializing and social well-being in children [5]. Previous studies have also shown that improving oral health can lead to improved communication, 
increased quality of life, as well as increased self-esteem and social confidence [5 and 6]. There are many factors contributing to poor oral health, some of which may include inadequate self-care, lack of access to oral health services, socio-economic factors, and personal obstacles and problems [6-8].

In this regard, World Health Organization has declared policy priorities for improving oral health as follows: effective use of fluoride, healthy nutrition, tobacco use control, improving the oral health of children and adolescents through school, promoting the elderly oral health, improving the oral health system, AIDS and oral health, improving the oral health information system and oral health research [9]. One of the strategies taken to implement these policies is to integrate oral health care with primary health care, so we can say that it has been a leading and correct strategy for accessing oral health care services for children and adolescents including fluoride therapy, visit and caries prevention [10].

According to the above, it seems that different communities need effective and practical management strategies and practices for achieving effective prevention in the field of oral health as well as reducing inequality and coverage of high-risk age groups. It also seems that the strategies proposed for developed countries do not work well in developing countries and globally [11]. Therefore, the purpose of this study is to identify the challenges and problems of oral health policy making in developing countries and especially Iran and present an effective solution for adopting effective policies and measures for improving oral health.

\section{Methods}

The present study was a qualitative one conducted in 2019 through content analysis. We used semistructured interviews with policy makers, oral health professors, managers and assistants involved in this field in this study. The purpose of performing these interviews was to explain the challenges of policy making in the field of oral health and the reasons for neglecting oral health in the upstream documents of the Islamic Republic of Iran. The interviewees were selected by snowball sampling method. First, Oral Health Officer of Shiraz University of Medical Sciences as the metropolitan area of the southern part of the country and his deputies were interviewed and then asked to identify those who are experts in the field. The study participants were well-informed and experienced in the field of oral health and policymaking, who spoke well and were willing to share their information. At this stage of the work, the interviews were performed with participants' opinion and prior coordination with them in person and preferably at their workplace. At the beginning of the interview, general explanations were given verbally about the study and its purpose, as well as the arrangements for keeping their information confidential. A written informed consent form was also obtained from all participants, and participants were assured that they were free to leave at any stage of the research that did not wish to continue. The interviews lasted at least 50 minutes and all interviews were performed by one of the researchers. The interviews were recorded with the consent of the participants and transcribed word by word shortly after the end of the interview. The interviews continued until saturation and after performing 12 interviews saturation was achieved. In order to provide a semi-structured interview guide consisting of 10 questions we used literature review approved by two management and policy experts in Shiraz University of Medical 
Sciences. The face validity of the interview guide was also confirmed by performing three initial interviews with the interviewees.

In order to increase the accuracy of the study, data were coded using the four Guba and Lincoln criteria such as acceptability, validity, reliability, and transferability, which are criteria for confirming the reliability of qualitative studies [12]. In order to enhance the validity of the study, long-term engagement and continuous observation were used, so that the researcher was fully engaged in the study, made proper communication with the participants and accepted the deeper concepts that emerged in the study process. The method of a combination of interview and literature review was also used. In order to increase the validity of the results, the coded data were provided to the participants to confirm the validity of the results. In order to improve the transferability of the study results, the conditions of the informed participants of the study and the method of interviewing were clearly defined. It was attempted to select the sample population based on the purpose of the study without any bias, to analyze the data at the same time as collecting data, and the researcher to be fully aware of the theoretical foundations of the study. In order to enhance the reliability of the study results, the coding of concepts and themes, as well as textual and audio information will be available. Also, in order to ensure reliability, two members of the research team individually analyzed the content and discussed for agreement on disagreements.

Five-stage framework analysis method was used to analyze the data. In order to identify the data at the first stage, the audio files of the meetings were heard several times by the researcher and the texts were read several times. At the second stage, in order to identify a thematic framework, the repeated ideas in the familiarization process were transformed into groups of similar ideas or codes. At the third stage, indexing, units, or parts of the data associated with a particular code are identified. At the fourth stage, after indexing, the data were summarized as a code table based on the thematic framework, and finally at the fifth stage, the data were finally combined, mapped and interpreted to define concepts and show the relationship between concepts to identify the nature of the phenomenon and provide explanations and suggestions [13]. The coding and categorization of the data were manually instead of using software because of the Persian text of the interviews and increase creativity. For this purpose, the challenges of oral health policy making and the reason for its neglect in the upstream documents of the Islamic Republic of Iran were identified.

\section{Results}

The analysis of the results of the interviews resulted in the identification of 7 main themes and 20 subthemes as described in Table 1. The main themes identified were challenges in policy making, implementing, educational, stewardship, prevention, insurance, and resource allocating.

As shown in Table 1, policy making challenges included four sub-themes: lack of policymakers, weakness in evidence-based policy making, differences in target groups, and conflicts of interest. The participants stated that lack of relevant policy makers in the field of oral health has caused weaknesses and problems in improving oral health. In this regard, a participant stated: 
"After the Islamic Revolution, a number of physicians received specialization. In addition to specialization and becoming a surgeon, internist, ophthalmologist, they became familiar with the management requirements of the modern world and health policy making and health economics, and advanced in the field of medicine, management and dentistry, who went on to pursue a career in dentistry, pursuing specialization, residency and business in the dental market with no attention to management and policy making in the field of dentistry, this is our major challenge: no manager and policy maker in the field of oral health" $\left(P_{1}\right)$.

In this regard, another interviewee stated:

"We educate social dentists here who are managing health care, policymaking with prevention, new ways of social grouping, and many topics that are related to the health system, and then coming into the field when practicing just education or finally a responsibility with no maneuver and who will go after is not a specialist, just a clinician, when dealing with a patient has no vision of community and health. $A$ prosthodontist is not aware of problems of the community and those with low social status, not know what they need in terms of oral health, cannot properly plan and execute prevention and health" $\left(P_{2}\right)$.

Another sub-theme of policy making was the lack of attention to evidence in oral health policy making. In this regard, one of the interviewees stated:

"When we ignore the evidence that proven prophylactic packages can improve oral health today, but we, for example, put free restoration packages, assuming everyone does this, it won't improve oral health. It becomes endo, then it breaks down, the root removed, we have this problem as long as there is no therapeutic approach and policy makers don't take a preventive approach" $\left(P_{3}\right)$.

In this regard, another interviewee said:

"I believe in the Ministry of Health plans, Oral Health is ignored, because the Ministry of Health goes the wrong way as people go. Because the policies of the Ministry of Health do not follow evidence-based policy making, the policies of the Ministry of Health are passive i.e. act when there is money, discontent or collapse, but there is no public demand for oral health. There is no need to change it. The Ministry of Health either because of resource constraints or because of a lack of understanding of complete benefit packages, lack of attention to dental health or lack of public demand did not seriously dealt with" $\left(P_{6}\right)$.

Other major themes in this study were educational challenges in the field of oral health which led to the identification of the sub-themes of "lack of appropriate educational curriculum", here is the statement of a participant:

"Inefficiency of educational rules", "educational structure", and "training of intermediate forces (oral health care providers)" $\left(P_{7}\right)$.

Furthermore, another interviewee said: 
"Dental curriculum is problematic, not being community oriented. This is a debate in our dental education. Let's see, in developed countries we have that number and the country may have had a successful dental education but this was not tailored to the needs of the community. The distribution of sources is not just" $\left(P_{11}\right)$.

Or in another place, the other interviewee said:

"Educational curriculum is not based on community needs. The curriculum should be changed and demographic conditions such as population aging should take a preventative approach and pay attention to the burden of non-communicable diseases by relying on common risk factors" $\left(P_{1}\right)$.

One of the sub-themes was the inefficiency of educational rules. In this regard, one of the interviewees stated:

"For years, the Ministry of Health accepted some people with lower dental facilities and ranks in dentistry who, after graduating, provided dental services in disadvantaged areas, but due to lack of proper education, this was not the case. We are faced with a shortage of dentists in deprived and underprivileged areas. On the other hand, dentists studying abroad have returned to the country due to a lack of specific legal mechanisms and have been educated in domestic colleges so that for example in Shiraz there are 800 surplus dentists according to international standards" $\left(P_{12}\right)$.

Regarding the structure and infrastructure of oral health education, the interviewees stated:

"At one point parliamentarians pushed and built a college in every city. A huge budget that should be spent on preventative dental health was for the dental colleges, which now stands forever to educate students with no administrator dares to close these colleges every year devours huge budgets and the dentist's job is broken" $\left(P_{1}\right)$.

Another interviewee stated:

"There are a lot of oral health budgets now spent for colleges that are not needed much. I think the number of colleges and students is much higher than needed, I remember, for example, a few years ago, a field work on oral health focused on increasing colleges and students was monitored by the World Health Organization and it was found that increasing the number of dentists and dental colleges did not have an effect on oral health state as the need assessment for dental care is different and not like medicine. For example, we cannot say that per 1000 persons we have a doctor, dental field is better, than the increase in general and special dentistry, multiple forces can be trained with limited responsibility and complete supervision that do not go beyond the scope of duties" $\left(P_{2}\right)$.

One of the sub-themes in the educational challenges was training oral health care forces as in this regard one of the participants stated: 
"It was very interesting at the beginning of the revolution when the health system went along with the training of health workers, dental hygienists, and we spent a lot for this health work, we said go to deprived areas, the entrance was made to convert health workers to dentists and then the training program of health workers stopped. This would indicate that the system should train health workers on an ongoing basis that they would turn to the dentists. We have intermediate forces. This is very important because dental services are expensive so if there is no intermediate force for oral hygiene to work on prevention, life style and tooth brushing we would have no advance in this field, and just being a dentist does not help, in other words no relationship was found between the development of dental colleges and oral and dental indices. We made available in the golden age of the health network system. But it was not continued because of the conflict of interest, which means that the dental colleges considered it as a rival and hindered" $\left(P_{4}\right)$.

The interviewees emphasized the topic of educating oral health practitioners and believed that training these forces could improve and develop the oral health state. In this regard, another participant stated:

"In order to promote oral health, we need to have intermediate forces, such as a dental technician's hygienist not like the present case. Dental technicians at some universities are now trained but due to lack of proper supervision they go to dentistry and sometimes they do specialized work while they have to do preventive and educational work, and despite having a commitment to serve in deprived areas, but that has not actually happened. The intermediate forces can be very effective for example in many developed countries due to high costs of training dentists intermediate forces are trained and tasks of preventing, educating and surface restorations are done that are very effective that will be faded if there is no proper monitoring" $\left(P_{7}\right)$.

The executive challenges were one of the main themes that led to the identification of sub-themes in the field of "service delivery", "health interventions" and "monitoring and evaluation":

In this regard, one of the interviewees stated:

"In the provision of dental services, no relationship is found between the private and public sectors, such as public and special problems in this field. Dentistry as a luxury field of study has its own costly services, difficulty and easy access is not yet fully established, network structure was available for this monitoring and now, and there seems to be a wandering of the structure of the sources and etc." $\left(P_{4}\right)$.

Or elsewhere, an interviewee said:

"In service delivery, there should be a leveling service, referral system.If the referral system is implemented, the service delivery will be improved as well, which of course requires intermediate forces to provide basic services and, if necessary, referring the patient to the dentist will save money and provide him with timely services" $\left(P_{3}\right)$.

Monitoring and evaluation as another sub-theme stated in this regard: 
"Monitoring and evaluation are very important, especially in national plans, and if the plans are not implemented effectively, I think due to lack of proper monitoring after implementation some of the prevention plans that have been implemented so far have failed. For example, we send our students for training in schools reporting that, for example, a 200-student school would have fluoride therapy one day, which would practically not yield a good result, indicating improper monitoring" $\left(P_{4}\right)$.

And / or in this regard another interviewee added:

"Much attention should be paid to the evaluation and monitoring of oral health plans, and the point to be made in this regard is the need for a supervisor and evaluator to be separated, unfortunately not the case now" $\left(P_{9}\right)$.

The design of health interventions was another sub-theme and the emphasis of the interviewees was on the need for serious attention to preventive interventions. For example, an interviewee stated:

"In terms of interventions, there has been an experience in Thailand, Thailand in terms of health system is among good countries. They have been increasing tools and dentists for many years but no change in dental health has worsened the case, investing in two areas of insurance based on training and providing simple tools such as toothbrushes, extensively at school level, wherever people work as a team and after a few years this changed indicators. It seems that it is the best things to do because the simple tool for a lot of people costs a lot, it is not included in the cost of purchasing and if such interventions are done certainly we obtain better results" $\left(P_{3}\right)$.

The insurance challenges were the other themes of the study that included the sub-themes of "target group coverage", "basic insurance package reform" and "attention to cost effectiveness of services". In this regard, the participants stated:

"In many European countries, children are insured since birth, examined every three or six months until the age of 18, and children and their parents are trained to do preventive activities such as fluoride therapy is compulsory just like vaccination even if a person does not refer. This prevents the burden of treatment. Nowhere else in the world dental insurance coverage is free because expensive services and high costs cannot be insured. This is possible when we undertake preventive work and provide coverage to persons under 12 years of age or surface repair. Restoration of teeth was implemented for 6 teeth but due to lack of proper supervision all refer for the restoration of teeth even if it is not required dentists do because receive per case and leads to the demand induction" $\left(P_{6}\right)$.

Other important challenge in this field that has been addressed in this study is the challenges of stewardship. Some participants stated:

"The stewardship should coordinate all the three departments of education, health and treatment. It is suggested to manage an office by the Minister to run all the three departments and coordinate accordingly. In the health sector in the twelfth government, an enormous and unprecedented amount of 
funding was provided to the oral health, over 300 billion, no one evaluated what the cost of effectiveness is. So, stewardship is poor in this sector. This is a major problem for treatment and HR and private centers were not distributed fairly. Once monitoring can be better controlled that any force works where you that is the problem of trusteeship that is better if it is considered as a unit" $\left(P_{2}\right)$.

Or another interviewee stated:

"No one is the responsible of stewardship. The universities have different practices, in fact, because the principal executives do not hire those who have both knowledge and expertise so we have these problems. That is to say, we need a single stewardship to control all fields of treatment and education" (P4).

And another interviewee noted:

"The task of the College is finally to train the human resources. The stewardship should return to the Ministry of Health. Health stewardship should be return to treatment, treatment has no dominance or interest for health. If treatment stewardship returned to health, health has no ability to manage the private sector and maybe its best is to separate the health and treatment and coordinate. So I believe that if health department is established, these two offices should be one to increase monitoring, and then experts in the field of prevention and experts in the field of treatment should work separately" $\left(P_{5}\right)$.

The challenges related to prevention were another topic that interviewees stated in this regard:

"In the field of health and prevention, the attraction of the treatment sector caused increasing the willingness to treatment and wealth. And the health care sector is not considered. The therapists are influential and take jobs for policy making. For example, the highest level of oral health policy making a prosthodontist, who cures a condition of a patient that has lost all of teeth and should provide with teeth. Definitely a person with this concept,or for years the principal for oral health policy making in the country was an endodontist, while, policy makers in the developed countries are specialized in oral health, social oral health. Many years ago, the government funded 6 or 7 persons in the field of social dentistry in the hope of returning later to and each manage the country oral health policies. All of them returned and became professors at universities, and all do is publish papers. In the Oral Health Policy finally, there should be somebody to point out these problems. Some are illiterate and some are not" $\left(P_{1}\right)$.

Or another interviewee mentioned elsewhere:

"The statistics presented are inaccurate. The layout looks appealing, but when we get into the treatment cycle, the amount of support we receive for dentistry is not enough and so expensive that one goes into the treatment cycle inevitably. The treatment package with a therapeutic approach is not very effective and should be a prevention approach and monitoring the method" $\left(P_{4}\right)$.

\section{Discussion}


The present study was conducted aimed to identify the challenges of oral health policy and to keep it in the upstream documents. The identified challenges were policy, trusteeship, execution, insurance, education and prevention challenges. It seems that attention to oral health for allocating resources and cost-effectiveness of its services is not as much of a concern for health decision makers and policy makers in the world, especially in developing countries, as some studies suggest [14 and 15]. As in this study, neglecting oral health in policy making and upstream documentation is one of the challenges in this field. The evidence-based policy making is one of the key topics highlighted by the World Health Organization. It develops strategies that should be the basis for policy making in developing countries, such as reducing the burden of oral diseases, improving lifestyles, developing a system of fair service in oral health, and developing a program-based policy making framework for community health promotions [16]. One of the policy making challenges in this study was the lack of effective health interventions and dentists' willingness to treat as well as the lack of effective policy making in the field of prevention. The dentists' willingness to be in the private sector and generate income in this sector is a common theme in most countries [17]. In spite of preventive policies by the Ministry of Health, as well as some emphasis in national documents, these interventions appear to still have weaknesses, including proper postimplementation evaluation and monitoring, which is essential for the Ministry of Health to adopt effective policies and payment system reform will eliminate this shortcoming. One of the challenges identified in this study was the high cost of training general practitioners and specialist dentists and not paying attention to the training of intermediate forces (oral hygienist, oral health care provider, and oral technician). It was found that the policy of increasing the number of dental colleges and training of dental specialists did not lead to improvement of oral health state. The evidence also suggest that in developing countries the policy of increasing and training intermediate forces can provide better results and help improve the oral health state of the community [18] so that it can reduce caries, increase and improve restoration as well as reducing dental emergencies especially in children. Other challenge is the current educational curriculum, which is not based on the present results based on epidemiology of oral diseases and community-based. Many studies around the world have also emphasized the importance of changing the educational curriculum of dentistry and the need to have goals such as effective prevention, health promotion, high communication skills, cognition of the social environment, and etc. [19 and 20]. Insurance coverage in oral diseases is a global challenge due to the high cost of services and the luxury of services. Some evidence suggest that insurance coverage emphasizes and prioritizes early prevention and treatment services with target groups' priority. It also results in less cost to the health system and has more health-related consequences [21]. Although some developed countries, including Japan, have covered their dental services under their insurance plan and have achieved good results in adopting uniform tariff policies in the private and public sectors [22]. But the topic of this study was insurance coverage of preventive services for developing countries, including Iran, which could have a better effectiveness. One of the challenges identified in this study was resource challenges consisting of human, physical and financial resources. Access to dental services includes dentistry and fair and equitable distribution and physical infrastructure, especially in deprived and underprivileged areas with oral health promotion problems referred to as care inversion. Various studies around the world have also addressed this problem and have doubled the need for attention [23 and 24]. One of the problems raised 
in this study was the weakness of the integrated information system and the accuracy of the data. Previous studies have also emphasized the importance of an integrated system for collecting and analyzing information in this field, which requires serious policy makers' attention [25].

Finally, another challenge discussed in this study was to pay attention to proper oral health. It seems that having an integrated stewardship in oral health is an important and influential issue in this field. Previous studies in this field suggest that stewardshipshould be integrated under the supervision of the monitoring of Office of Oral Health. So that the tasks of policy making and enforcing these policies in the public and private sectors are considered [26].

\section{Conclusion}

The study results show that serious attention to the oral health and efforts to improve it in macro health policy making is neglected and regarding the importance of oral health, serious review of educational, preventive and therapeutic policies is needed. On the other hand, according to the present results, it seems that national coverage of oral health and the integration of these services in prevention services and serious attention to the private sector can be considered as the most important strategies for achieving improved oral health.

\section{Declarations}

\section{- Ethic committee's approval and consent to participate}

The article`s proposal is approved by ethics committee affiliated with Shiraz University of Medical Sciences with the ID of SUMS-98-01-07-20930.

\section{- Consent for publication}

Not applicable

- Availability of data and material

All The data is available in a form of data extraction sheets.

\section{- Competing interests}

All authors declare that they have no conflict of interest regarding this study.

\section{- Funding}

This study was sponsored by Shiraz University of Medical Sciences under code (98-01-07-20930).

\section{- Authors' Contributions}

PB has designed the study and finalized the whole data analysis. She also supervised the study. MMP and JB have collected the data and extracted and initially analyzed them. They also prepared the initial 
draft of the manuscript. AG has translated, technically edited and finalized the whole article.

\section{- Acknowledgements}

Authors would like to thank Shiraz University of Medical Sciences for supporting to conduct the study.

\section{References}

1. Health, U.S. D.o., et al., Oral health in America: a report of the Surgeon General. 2000, Department of Health and Human Services Rockville.

2. Vos, T., et al., Global, regional, and national incidence, prevalence, and years lived with disability for 328 diseases and injuries for 195 countries, 1990-2016: a systematic analysis for the Global Burden of Disease Study 2016. The Lancet, 2017. 390(10100): p. 1211-1259.

3. Jadidfard, M.-P., S. Yazdani, and M.-H. Khoshnevisan, Social insurance for dental care in Iran: a developing scheme for a developing country. Oral Health Dent Manag, 2012. 11(4): p. 189-98.

4. Bastani, P., et al., Qualitative analysis of national documents on health care services and pharmaceuticalspurchasing challenges: evidence from Iran. BMC health services research, 2018. 18(1): p. 410.

5. Association, L. G., Tackling poor oral health in children. London: Local Government Association, 2016.

6. Locker, D., Measuring oral health: a conceptual framework. Community Dent Health, 1988. 5: p. 318.

7. Newton, J. T. and E. J. Bower, The social determinants of oral health: new approaches to conceptualizing and researching complex causal networks. Community dentistry and oral epidemiology, 2005. 33(1): p. 25-34.

8. Patrick, D. L., et al. Reducing oral health disparities: a focus on social and cultural determinants. in BMC oral health. 2006. BioMed Central.

9. Petersen, P. E., World Health Organization global policy for improvement of oral health-World Health Assembly 2007. International dental journal, 2008. 58(3): p. 115-121.

10. subcommittee, A. A.o.P. D.C. A. C.-P. T., American Academy on Pediatric Dentistry Council on Clinical Affairs: Guideline on pulp therapy for primary and young permanent teeth. Pediatr. Dent., 2009. 30(7): p. 170-174.

11. Williams, D. M., P. A. Mossey, and M. R. Mathur, Leadership in global oral health. Journal of dentistry, 2019. 87: p. 49-54.

12. Guba, E. G. and Y. S. Lincoln, Competing paradigms in qualitative research. Handbook of qualitative research, 1994. 2(163-194): p. 105.

13. Gale, N. K., et al., Using the framework method for the analysis of qualitative data in multidisciplinary health research. BMC medical research methodology, 2013. 13(1): p. 117.

14. Hollingsworth, B., International Health Economics Association: Student prize competition. Health economics, 2017. 26(9): p. 1093-1093. 
15. Benzian, H., et al., Political priority of global oral health: an analysis of reasons for international neglect. International dental journal, 2011. 61(3): p. 124-130.

16. Petersen, P. E., Improvement of global oral health-the leadership role of the World Health Organization. Community Dent Health, 2010. 27(4): p. 194-198.

17. Tomar, S. L. and L. K. Cohen, Attributes of an ideal oral health care system. Journal of public health dentistry, 2010. 70: p. S6-S14.

18. Simmer-Beck, M., et al., Effectiveness of an Alternative Dental Workforce Model on the Oral Health of Low-Income Children in a School-Based Setting. American journal of public health, 2015. 105(9): p. 1763-1769.

19. McHarg, J. and E. Kay, Designing a dental curriculum for the twenty-first century. British dental journal, 2009. 207(10): p. 493.

20. McHarg, J. and E. Kay, The anatomy of a new dental curriculum. British dental journal, 2008. 204(11): p. 635.

21. Services, I.o.M. U. D.o.H. C., Public Policy Options for Better Dental Health: Report of a Study. Washington (DC): National Academies Press (US). 1980.

22. Zaitsu, T., T. Saito, and Y. Kawaguchi, The Oral Healthcare System in Japan. Healthcare (Basel, Switzerland), 2018. 6(3): p. 79

23. Freitas, D. J., et al., Oral health and access to dental care among older homeless adults: results from the HOPE HOME study. Journal of public health dentistry, 2019. 79(1): p. 3-9.

24. Daly, B., et al., Oral health care needs and oral health-related quality of life (OHIP-14) in homeless people. Community dentistry and oral epidemiology, 2010. 38(2): p. 136-144.

25. AbouZahr, C. and T. Boerma, Health information systems: the foundations of public health. Bulletin of the World Health Organization, 2005. 83(8): p. 578-583.

26. Tahani, B., Stewardship of National Oral Health system in Iran: Its strengths and weaknesses. Archives of Iranian medicine, 2013. 16(12): p. 717.

\section{Table}

Table 1 - Main themes and sub-themes of policy making challenges in the field of oral health of the Islamic Republic of Iran 


\begin{tabular}{|c|c|c|}
\hline Main themes & Sub-themes & Final codes \\
\hline \multirow{20}{*}{$\begin{array}{l}\text { Executive } \\
\text { challenges }\end{array}$} & \multirow[t]{7}{*}{ Health care interventions } & Design of therapeutic interventions \\
\hline & & The high cost of treatment centered plans \\
\hline & & The need to design comprehensive and fair plans \\
\hline & & Fair access to services \\
\hline & & $\begin{array}{c}\text { Pay attention to prevention in the design of } \\
\text { intervention }\end{array}$ \\
\hline & & Leveling Services \\
\hline & & $\begin{array}{l}\text { Considering the cost effectiveness of package } \\
\text { design }\end{array}$ \\
\hline & \multirow[t]{5}{*}{ Monitoring and evaluation } & $\begin{array}{c}\text { Lack of cost-effectiveness assessments of oral } \\
\text { health plans } \\
\end{array}$ \\
\hline & & $\begin{array}{c}\text { Separation of the evaluation team from the } \\
\text { implementation }\end{array}$ \\
\hline & & Lack of a proper evaluation system \\
\hline & & $\begin{array}{c}\text { Lack of a proper monitoring and evaluation } \\
\text { protocol }\end{array}$ \\
\hline & & $\begin{array}{l}\text { Problem monitoring due to the complexity of } \\
\text { services }\end{array}$ \\
\hline & \multirow[t]{4}{*}{ Service delivery } & Pay attention to the burden of diseases \\
\hline & & Serious attention to the referral system \\
\hline & & $\begin{array}{c}\text { Necessary to design appropriate service } \\
\text { structure }\end{array}$ \\
\hline & & $\begin{array}{c}\text { Provide preventive and effective care by } \\
\text { intermediate forces }\end{array}$ \\
\hline & \multirow[t]{4}{*}{ Oral Health Information System } & Inappropriate analysis of oral health state \\
\hline & & $\begin{array}{c}\text { Mismatch of statistics and information with } \\
\text { existing situation }\end{array}$ \\
\hline & & $\begin{array}{c}\text { Necessity of designing a strong and efficient } \\
\text { information system }\end{array}$ \\
\hline & & Lack of an integrated information system \\
\hline \multirow{14}{*}{$\begin{array}{l}\text { Educational } \\
\text { challenges }\end{array}$} & \multirow[t]{4}{*}{ Educational curriculum } & Treatment-based education curriculum \\
\hline & & $\begin{array}{l}\text { The educational curriculum is not community- } \\
\text { based }\end{array}$ \\
\hline & & Need-based curriculum Change \\
\hline & & Attention to prevention in students' curriculum \\
\hline & \multirow[t]{5}{*}{ Educational rules } & Educational wrong policy making \\
\hline & & Lack of policy-making for oral health education \\
\hline & & Inefficiency of the Human Resources Plan Act \\
\hline & & Strong regulatory for hiring intermediate forces \\
\hline & & $\begin{array}{l}\text { Necessity of intervention and implementation of } \\
\text { the obligations of trained forces }\end{array}$ \\
\hline & \multirow[t]{5}{*}{ Educational infrastructure } & Weaknesses in educational need assessment \\
\hline & & Hiring Social Dentistry Graduates \\
\hline & & Declining dental schools \\
\hline & & $\begin{array}{l}\text { The cost of undesired effectiveness of increasing } \\
\text { dental colleges }\end{array}$ \\
\hline & & Dental colleges beyond need \\
\hline
\end{tabular}




\begin{tabular}{|c|c|c|}
\hline & & Training of a dental specialist is overly needed \\
\hline & & Convert some colleges to clinics \\
\hline & & $\begin{array}{c}\text { Lack of impact of increasing colleges on } \\
\text { improving indicators } \\
\end{array}$ \\
\hline & Training of intermediate forces & Oral Health worker Education \\
\hline & (technician, hygienist, and oral health & Using educational interfaces for schools \\
\hline & care) & The Cost of training a Dentist \\
\hline & & Effectiveness of intermediate forces \\
\hline & & Low cost of training intermediate forces \\
\hline & & Successful experiences of intermediate forces \\
\hline Policy & Lack of policy makers & Lack of policy maker in the field of oral health \\
\hline $\begin{array}{l}\text { making } \\
\text { challenges }\end{array}$ & & $\begin{array}{c}\text { The presence of therapists at the top of policy } \\
\text { making }\end{array}$ \\
\hline & & Non-hire of social dentists \\
\hline & & $\begin{array}{l}\text { Weakness in policy making knowledge and } \\
\text { health economics among policymakers }\end{array}$ \\
\hline & & Lack of relevant policymakers \\
\hline & & Neglecting Social Dentistry in Policy Making \\
\hline & & Lack of relevant policymakers \\
\hline & Evidence-based policy making & $\begin{array}{l}\text { The policymaker's view of dentistry as a luxury } \\
\text { service }\end{array}$ \\
\hline & & The therapeutic approach in policy making \\
\hline & & Designing native health packages \\
\hline & & Lack of evidence-based policymaking \\
\hline & & $\begin{array}{l}\text { Lack of awareness of full service package of } \\
\text { policy making }\end{array}$ \\
\hline & & $\begin{array}{l}\text { Serious attention to supply and demand in } \\
\text { policymaking }\end{array}$ \\
\hline & Conflict of interest & Necessity to reduce profession and union look \\
\hline & & $\begin{array}{c}\text { Conflict of interest in training intermediate } \\
\text { forces }\end{array}$ \\
\hline & & Conflict of interest in policy making \\
\hline & & Transparency in the public and private sectors \\
\hline & & $\begin{array}{c}\text { Protecting corporate interests in the face of } \\
\text { wrong measures }\end{array}$ \\
\hline Trusteeship & Unit trusteeship & Multiple trusteeship in the field of oral health \\
\hline challenge & & $\begin{array}{c}\text { Necessity of coordination of all three } \\
\text { departments of education, health and treatment }\end{array}$ \\
\hline & & Difficult to enforce policies \\
\hline & & $\begin{array}{l}\text { Multiple decision making in the field of oral } \\
\text { health }\end{array}$ \\
\hline & & Single trusteeship with separate experts \\
\hline & & Private sector trusteeship \\
\hline & & Wandering over resources and structure \\
\hline & Monitoring and coordination & Dividing tasks in the trusteeship \\
\hline & & $\begin{array}{l}\text { Appropriate trusteeship and attention to the } \\
\text { private sector }\end{array}$ \\
\hline & & $\begin{array}{c}\text { Coordination and monitoring of public and } \\
\text { private sectors in service provision }\end{array}$ \\
\hline
\end{tabular}




\begin{tabular}{|c|c|c|}
\hline & & No oral health plan at the Ministry of Health \\
\hline \multirow{11}{*}{$\begin{array}{l}\text { Prevention } \\
\text { challenges }\end{array}$} & \multirow{4}{*}{$\begin{array}{l}\text { Priority of treatment to prevention in } \\
\text { policy making }\end{array}$} & Dentists' desire for treatment \\
\hline & & More revenue in the field of treatment \\
\hline & & Resource allocation to prevention \\
\hline & & Pay attention to self-care \\
\hline & \multirow[t]{7}{*}{ Ignore the prevention debate } & Not paying attention to prevention \\
\hline & & Design of prevention-based interventions \\
\hline & & Prioritize for prevention \\
\hline & & Lack of prevention attitude in policymakers \\
\hline & & Use inexpensive prevention tools \\
\hline & & Lack of proper prioritization in oral health \\
\hline & & $\begin{array}{l}\text { Inadequate understanding of prevention in } \\
\text { intervention design and policy making }\end{array}$ \\
\hline \multirow{10}{*}{$\begin{array}{l}\text { Insurance } \\
\text { challenges }\end{array}$} & \multirow[t]{4}{*}{ Target groups } & Pay attention to target groups \\
\hline & & High-risk age group coverage \\
\hline & & $\begin{array}{l}\text { Lack of coverage for high disease burden age } \\
\text { group }\end{array}$ \\
\hline & & Elderly insurance coverage \\
\hline & \multirow[t]{6}{*}{ Correction of basic benefit package } & Dental services under insurance coverage \\
\hline & & Need to modify basic insurance package \\
\hline & & $\begin{array}{c}\text { Expensive services and unwillingness of } \\
\text { insurance }\end{array}$ \\
\hline & & Target groups basic insurance \\
\hline & & $\begin{array}{c}\text { Pay attention to the burden of diseases on the } \\
\text { insurance package }\end{array}$ \\
\hline & & Poor insurance coverage \\
\hline \multirow{10}{*}{$\begin{array}{l}\text { Resource } \\
\text { challenges }\end{array}$} & \multirow[t]{2}{*}{ Financial resources } & Lack of optimal allocation of funds \\
\hline & & Lack of clear financial resources \\
\hline & \multirow[t]{4}{*}{ Human resources } & Dentist training as needed \\
\hline & & Density of dentists in centers \\
\hline & & HR Needs Assessment \\
\hline & & Improper distribution of dentists \\
\hline & \multirow[t]{4}{*}{ Physical Resources } & Necessary equipment and infrastructure \\
\hline & & $\begin{array}{c}\text { Infrastructure and equipment needed in deprived } \\
\text { areas }\end{array}$ \\
\hline & & $\begin{array}{c}\text { Lack of infrastructure and facilities at } \\
\text { prevention centers }\end{array}$ \\
\hline & & Infrastructure burnout in deprived areas \\
\hline
\end{tabular}

